\title{
EDITORIAL
}

\section{Invisibility of Midwifery}

\author{
Andrea Gilkison
}

Co-editor

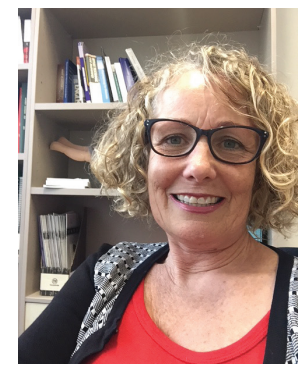

Recently I spent the day listening to third-year midwifery students presenting cases of women they had cared for, who had challenged them in some way. Those stories were incredible as the students discussed the midwifery care they had provided for women and babies with complex obstetric, neonatal, social, health and mental issues. They spoke about caring for teenage mothers, immigrants, women who do not speak English, women in violent relationships, women with mental health issues. They shared the way they cared for women whose babies were growth restricted, or women who wanted a vaginal birth and whose babies were breech. They shared how they traversed the primary/secondary interface and worked interprofessionally in their work to advocate for women and to ensure optimum care for mothers and babies.

I was so heartened to hear the way these soon-to-be midwives provided absolutely excellent midwifery care for these women. Whether it be liaising with social services, making multiple home visits, or advocating with the consultant for a vaginal breech birth, these students did it all and in such a professional way. How lucky are the women of New Zealand to have these midwives at their sides. It is mind blowing the care that midwives provide, and this should be shouted from the roof tops! Yet this incredible day-today work of midwives in New Zealand is often invisible to all except the woman and her whānau.

The invisibility of midwifery struck me again at the International Confederation of Midwives Congress in Toronto in June. Midwives were invisible in the poorest parts of the world which lack the most basic resource. On the other end of the spectrum, in wealthy parts of the world with incredibly high Caesarean Section rates, again there are no midwives. Whether it is a lack of resource, or a lack of valuing the work of the midwife, midwifery is invisible. Even in New Zealand, the real day-to-day work of a midwife is often invisible. This includes being invisible to the Ministry of Health it appears, although the threat of a high court case from the College has resulted now in making the work of a midwife visible and instigating the co-design of the funding model for $\mathrm{New}$ Zealand midwives. The co-design is based on visibility and pay equity for all midwives, employed and self-employed.

It was so heartening to read the story in the New Zealand Herald in April this year in which the parents of a baby born following a cord prolapse named midwife Sue Bree as a superhero. Sue was quoted as humbly saying "the services.... did well. It wasn't any one person, it was all the services." Just another day in the life of a midwife. Stories like this should be told more often, as it makes our work visible. As individual midwives it takes a lot of energy to make oneself visible, but as a profession we can work together to make the work of a midwife not only visible, but up in lights.

Each of the seven articles published in this issue of the NZCOM Journal does much to add to the visibility of midwifery. Morgan Weathington et al. explore the literature around the risk of stillbirth, and a Japanese study of third stage management shows the world that the midwifery profession has a lot to add to evidence-based practice. Three pieces of research exploring midwifery education establish the uniqueness of midwifery education models in New Zealand. Mary Kensington et al. have researched the use of groups in a blended model of undergraduate midwifery education and Jean Patterson et al. have researched the important topic of improving the experience for Māori midwifery students. Continuing in the area of education, Suzanne Miller and Christine Griffiths present findings of their study of how online postgraduate midwifery education enhances midwifery practice. In the sphere of midwives' wellbeing and the sustainability of midwifery practice, Lesley Dixon et al. present findings from a study which explored the important issue of the emotional wellbeing of New Zealand midwives, and Andrea Gilkison et al. present their research on what is at the heart of core midwifery.

Thank you to all the authors who submit articles to our Journal. The quality of the research published is high, and each article adds to midwifery knowledge, to evidence-based practice and to midwifery's visibility! I hope you enjoy reading these articles, and reflect on how we can work together to ensure the world hears about the less visible parts of the work of a midwife.

https://doi.org/10.12784/nzcomjn153.2017.0.4 